EMPLOYEE PERFORMANCE OUTCOMES AND BURNOUT FOLLOWING THE PRESENTATION-OF-SELF IN CUSTOMER-SERVICE CONTEXTS

Catherine Prentice Swinburne University, Australia Poju Chen University of Central Florida USA Brian King Hong Kong Polytechnic University 


\begin{abstract}
This study examines how emotional intelligence and occupational commitment have a moderating effect on the relationship between emotional labor and its potential outcomes. Two acting strategies reflect emotional labor, namely surface and deep acting, with burnout and performance as the prospective outcomes. Burnout is operationalized into emotional exhaustion, depersonalization and diminished personal achievement; whereas performance is operationalized into task performance and organizational citizenship behaviour (OCB). The study investigates employee responses from several tourism and hospitality organizations in Florida, USA. The results show that emotional labor relates most positively to task performance and to burnout in the case of surface acting. Tests of moderation show that occupational commitment enhances performance outcomes by facilitating emotional labor strategies, and the prevalence of higher emotional intelligence amongst employees reduces burnout. These findings contribute to the literature on emotional labor by incorporating emotional intelligence and occupational commitment as moderators and by incorporating OCBs within performance analyses.
\end{abstract}

Keywords; burnout; occupational commitment; emotional intelligence; emotional labor; organizational citizenship behavior; task performance, moderation.

\title{
Introduction
}


Emotional labor (EL) has been discussed extensively in the relevant literature, consistent with the importance of services to the economy and the increasing application of dramaturgical perspectives to the study of customer interactions. Defined by Hochschild (1983) as managing emotions through surface or deep acting by following organizational display rules in return for a wage, EL designs provide a means of enhancing task performance and a strategy for the effective management of service encounters through appropriate acting. Various researchers (Brotheridge \& Grandey, 2002; Mann \& Cowburn, 2005; Surana \& Singh, 2009) have reached broad agreement that deep acting leads to task effectiveness; whereas surface acting has negative consequences. However, a conceptual study by Ashforth and Humphrey (1993) argued that both acting strategies executed by frontline employees in service roles may lead to unfavourable outcomes by triggering negative connotations such as emotive dissonance and self-alienation. Drawing on this study, the present paper re-examines the relationship between emotional labor and the two most cited outcomes for frontline roles in the service context, namely performance and burnout.

Despite its likely effect on employee performance, EL is widely acknowledged as having detrimental effects on the workforce including burnout (e.g., Brotheridge \& Grandey, 2002; Johnson \& Spector, 2007; Montgomery, Panagopolou, Wildt, \& Meenks, 2006. Given that EL commonly forms part of the job descriptions of frontline employees, the factors facilitating the EL process should be identified in order to improve employee performance and ameliorate unfavourable consequences. Such factors are generally referred to as moderators (Baron \& Kenny, 2009). Previous research has been primarily focused on the antecedents and consequences of EL. The present study sheds lights on EL research by examining the remedy (moderator) with a view to enhancing the applicable outcomes. Adopting a social identity theory perspective, Ashforth and Humphrey (1993) have indicated that individuals tend to "act” appropriately by conforming to organizational display 
rules in identifying with their occupations. An introverted salesperson may for example, act in an extrovert manner in order to achieve sales effectiveness when identifying with the selling role. Witt's (1993) study shows that occupational identification has a positive effect on the level of commitment that is shown, which indicates greater commitment on the part of those who identify strongly with their occupations. These studies show that occupational commitment may moderate EL and its performance outcome.

EL Proponents argue that appropriate acting by frontline employees when dealing with various personal encounters enhances organizational effectiveness. Such encounters are emotionally loaded, particularly in the case of dealings with unreasonable and emotional customers (Daus \& Ashkanasy, 2005). The employees are under a strong compulsion to “act” hard in order to make customers satisfied, often leading to negative consequences. The prevalence of emotional skills on the part of employees (or labourers), may facilitate the service transaction by managing and regulating emotional encounters, thus lessening potentially negative outcomes. Hartel, Barker and Barker (1999) note that customer-contact employees who possess greater emotional intelligence manage service encounters more effectively. Emotional intelligence offers the prospect of facilitating either EL acting strategy and lessening its negative consequences.

Consistent with the discussion noted above, the current study proposes occupational commitment and emotional intelligence as moderators and examines their prospective moderating effects on EL outcomes. In particular the research explores the effect of occupational commitment on the relationship between EL and job performance, and the effect of emotional intelligence on the relationship between EL and burnout. Job performance is operationalized into task and contextual performance and burnout into emotional exhaustion, diminished personal achievement and depersonalisation. The proposed 
relationships are outlined in Figure 1. The following section provides a review of the relevant literature and a rationale and hypotheses to support the proposed model.

\section{Emotional labor and performance}

Emotional labor includes enhancing, faking, or suppressing emotions in order to modify the expression of emotions (Hochschild, 1983). It involves two main categories of performance. Firstly, the employee may engage in surface acting to comply with the prevailing rules of display. This type of acting involves simulating emotions that are not felt, and feigning emotions that are not experienced. The second type of performance involves deep acting - making a genuine attempt to experience or feel the emotions that are on display. Research into the EL concept focuses primarily on frontline service industry personnel, and has strong applicability to service encounters. Daus and Ashkanasy (2005) indicate that service roles involve a substantial EL component. On the basis that employees occupy the interface between an organization and its customers and form the first point of contact for customers, EL also has a high social component. Service transactions often involve face-toface interactions between employees and customers (Ashforth \& Humphrey, 1993).

According to Hochschild (1983), the display feelings of the EL process during service interactions have a strong impact on the quality of service transactions and on the attractiveness of the interpersonal climate and experience of emotions. Dynamic encounter communications may be enhanced where service employees have acquired prescribed sets of responses and patterns of EL-related behaviours (Mann, 1997). This can lead to increased product sales and to effective complaints handling, thereby ensuring smooth interactive communications (Hochschild, 1983). In combination, these should ultimately lead to better performance. Though previous research has reported a positive relationship between EL and job performance, EL researchers are in general agreement that only deep acting leads to the 
enhancement of performance which is typically referring to task performance in particular (e.g. Brotheridge \& Lee, 2002; Gradey, 2003).

Enhanced performance may follow from both task performance (in-role behaviours), and contextual performance which is often referred to as organization citizenship behaviours (OCBs) (Borman \& Motowidlo, 1997; Carmeli \& Josman, 2006; Rousseau, 1995). Task performance refers to employer expectations and requirements of employee behaviours or work performance in return for remuneration (see Borman \& Motowidlo, 1997). In the case of frontline service employees, such performance may concern customer evaluations of service quality leading to satisfaction and loyalty, and ultimately to company profitability (e.g., Zeithaml, Berry \& Parasuraman, 1996; Prentice \& King, 2012; Singh, 2000). OCBs include "individual behaviours that are discretionary, not directly or explicitly recognised by the formal reward system, and in the aggregate promote the efficient and effective functioning of the organization” (Organ, 1988, p 4). These behaviours are important for improving organizational efficiency and effectiveness and have an indirect effect on customer perceptions of the quality of the firm. A combination of task performance and OCBs is more indicative of employee performance. Previous EL-related studies have focused exclusively on a single dimension and have failed to capture the holistic picture of performance evaluation. On the basis of the foregoing discussion, the present study will investigate the prospective effects of surface or deep acting on both task performance and OCBs.

Surface acting involves a superficial display of emotions and circumstances where employees act because they are required to conform to organizational display rules. Whereas deep acting involves making a genuine effort to experience or feel emotions, it is largely voluntary and has a strong association with employee conscientiousness. OCBs may be conceptualised as employee behaviours that extend beyond the formal requirements of the designated role. Since the activities are not remunerated, such behaviours are discretionary 
and demand a level of conscientiousness. Since the acting of employees should be perceived as "real” OCBs require sincerity. Previous research has shown that task performance is affected positively by deep acting and negatively by surface acting. It seems likely that both forms of acting will have a similar influence on OCBs and this proposition leads to the following hypothesis:

\section{H1: Surface acting has negative influence whereas deep acting has positive}

\section{influence on task performance and $O C B$.}

\section{Occupational commitment as a moderator of EL}

The hypothesis indicates that the performance evaluations of those who are unable to engage in deep acting may be retarded. This suggests the importance of identifying factors that may adjust EL and enhance performance outcomes. Social identity theorists indicate that individuals who identify strongly with their occupation feel more authentic in conforming with organizational display rules, and are most truly themselves when fulfilling their roles (Ashforth \& Humphrey, 1993; Suh, Houston, Barney \& Kwon, 2011). The theory suggests that the type of "acting” that is described in the EL process and is expected by the organisation as a component of the rules of display may be enjoyable for occupants who are attached and committed to their occupations. Alternatively occupants may be capable of ‘acting’ effectively, thereby performing better. In this sense, occupational commitment may alter the effects of EL strategy as a potential moderator of the outcomes.

Occupational commitment has been proposed as an extension of organizational commitment and consists of three dimensions (see Meyer, Allen \& Smith, 1993). These are respectively: commitment as an affective attachment to occupation (affective occupational commitment), as a perceived cost associated with leaving the occupation (continuance occupational commitment), and as an obligation to remain in the occupation (normative occupational commitment) (Meyer et al., 1993). Individuals with strong occupational 
commitment are likely to achieve better individual and organizational outcomes (see Cohen, 1991; 2007; Riveros \& Tsai, 2011). Chang’s study (1999) shows that career commitment moderates the relationship between organizational commitment and turnover intention. The study indicates that occupational commitment may enhance job satisfaction and reduce employee turnover. Those who are happy with and committed to their jobs and/or careers may perform well at work. In the case of the emotional laborer, job satisfaction may facilitate the acting process and enhance performance outcomes. Consistent with the above discussion and in alignment with social identity theory, the following hypothesis is proposed:

\section{H2: Occupational commitment moderates the influences of emotional labour on}

\section{performance outcomes.}

A review of the relevant literature shows that previous EL related research has been primarily focused on its unfavourable consequences. Burnout is the most commonly researched of the various negative connotations (e.g., Brotheridge, \& Grandey, 2002; Johnson \& Spector, 2007; Montgomery, Panagopolou, Wildt, \& Meenks, 2006). Researchers generally believe that burnout is positively related to the surface acting element of the EL process but is negatively related to deep acting (e.g. Brotheridge \& Grandey, 2002; Grandey, 2003; Kim, 2008). Portraying emotions that are not felt (surface acting) may create emotive dissonance that is akin to cognitive dissonance (Hochschild, 1983). Such dissonance may cause the employee to feel false and hypocritical, leading ultimately to personal and workrelated maladjustments such as poor self-esteem, depression, cynicism and alienation from work (Ashforth \& Humphrey, 1993; Fineman, 1993; Seeman, 1991).

Some others (e.g., Ashforth \& Humphrey, 1993; Mikolajczak, Menil, \& Luminet, 2007) hold a different view and assert that both acting strategies have negative outcomes in the case of demanding jobs such as frontline positions or so-called job-focused emotional labor where the employee exercises minimal control (Brotheridge \& Grandey, 2002; Pugliesi, 
1999). Drawing on Darwin's view that emotional reactions serve as a signal function, helping one to make sense of situations and connecting one to others and to the context, Ashforth and Humphrey (1993) indicate that deep acting may distort employee reactions and impair one's sense of the authentic self. This outcome may ultimately lead to self-alienation and reduced capacity to recognize or even to experience genuine emotions. The reworking of authentic emotions (deep acting) has been found to be positively associated with psychological dysfunctions and overall stress (Parkinson, 1991; Rutter \& Fielding, 1988). Such stress may lead ultimately to burnout. Indeed, Mikolajczak et al.’s (2007) study demonstrated a positive relationship between deep acting and burnout, leading to the formulation of the following hypothesis:

H3: Within the EL process, surface and deep acting influence burnout positively in the case of customer-contact roles.

\section{Emotional intelligence as a moderator of EL}

The incidence of burnout has negative consequences for individuals and also for organisations such as low employee self-esteem, health problems, absenteeism, accelerated turnover, job dissatisfaction and poor performance with serious consequences (see Dahlin, Joneborg, \& Runeson, 2007; Houkes, Janssen, Jonge, \& Nijhuis, 2010; Pienaar \& Willemse, 2008). Such consequences have prompted researchers and practitioners to investigate potential remedies. Emotional intelligence may offer a potential remedy for regulating prospective negative consequences.

Emotional Intelligence is conceptualized as the ability to perceive, respond and manipulate emotional information without necessarily understanding it and the ability to understand and manage emotions without necessarily perceiving feelings well or experiencing them fully (Salovey \& Mayer, 1997). The construct has particular relevance to frontline personnel and their job-related outcomes because their employment involves 
substantial interpersonal interactions that require emotional work (Ashforth \& Humphrey, 1993; Ashkanasy \& Daus, 2005). Emotional intelligence can shape customer reactions towards service failure as well as facilitating the capacity to deal with workplace-related stress (Ashkanasy, Jordan \& Ashton-James, 2003; Douglas, Frink \& Ferris, 2004; Gabbott, Tsarenko, \& Mok, 2011). Consequently, such emotional skills may moderate the employee (laborer) acting process. The hierarchical model of emotional intelligence proposed by Mayer, Salovery, Caruso, and Sitarenios (2001) may help to explain the prospective moderating effect.

Of the four hierarchical branches of emotional intelligence outlined by Mayer et al. (2001) the first involves emotional perception. This refers to an ability to identify and express emotions, and to discriminate the expression of various feelings. The second branch emotional assimilation - includes emotion-prioritised thinking by directing attention towards important information. Emotional mood swings may, for example, change an individual's perspective from optimistic to pessimistic, whereas happiness facilitates inductive reasoning and creativity. The third branch, emotional understanding, involves the ability to label and recognise emotions and emotional transitions, for instance, the transition from anger to satisfaction, and the ability to understand complex feelings. The fourth branch, emotions management, includes the ability to stay open to feelings, to engage or detach from an emotion, to monitor emotions and to manage emotions in self and others by moderating negative emotions and enhancing pleasant ones. The four hierarchical branches may be capable of adjusting the EL process.

The first branch may influence surface acting (simulating emotions that are not actually felt) and may be explained as follows. Emotions can only be simulated effectively in circumstances where the perception is accurate, thereby allowing the simulation to fit the context. A nurse may for example simulate sympathy for a patient who has deep concerns 
about his or her health. In this circumstance the process of simulation is dependent on the nurse possessing the required perception of the patient's concerns. The fourth branch can facilitate deep acting (attempts to experience or feel the emotions that one wishes to display). Mayer et al. (2001) indicated that the four branches function hierarchically. The perception of emotions acts as both the most basic branch and as a precursor of the others. As an occupant of the top branch, emotional management may be viewed as the most complex. Once a perception has been acquired, emotions may be deployed in order to facilitate conscious or unconscious thought, leading to an adjustment of feelings (Levine, 1997; Mayer et al., 2001). On this basis, the following hypothesis is proposed:

H4: Emotional intelligence moderates the influence of emotional labor on burnout.

\section{Method}

\section{Participants}

The literature review supports the view that EL is particularly relevant in the case of encounters between frontline representatives and customers. The respondent sample that was used for the purposes of the present investigation consisted of hospitality service employees. The study instrument was validated by key informants consisting of two scholars and five hospitality and tourism industry managers in Florida, USA. It was then pilot tested with a convenience sample of university hospitality management students. The pilot test was confined to students enrolled at the University of Central Florida, who are also engaged in full-time employment in hospitality and tourism and who occupy guest encounter roles.

The questionnaires that were used in the pilot test were subsequently modified on the basis of inputs provided by key informants and participants. Relevant modifications were applied with a view to improving face validity and readability. Prospective respondents were provided with instructions requesting that only those occupying customer contact roles 
should complete the questionnaires. As indicated by Ashforth and Humphrey (1993), such employees are involved in performing emotions-based work.

The researchers contacted over 20 hospitality organizations in Florida, USA. Five of the recipients granted permission for the researchers to administer the study to their customer-contact employees. In the case of each of the five organisations the human resources manager provided an endorsement of the study to employees. Paper-and-pencil surveys were delivered either to the participants or were provided in the employee refreshment area.

The human resources manager disseminated a message announcing a draw of raffle tickets for two $\$ 100$ gift cards to employees with a view to encouraging participation. Participants received a raffle number on returning their completed questionnaires to the researchers and the winners were announced at the end of survey period. Reminders were sent to employees two weeks after the first visit. Of the 1,000 surveys distributed, 578 usable responses were returned (58\%). Of the total usable sample, 260 (45\%) were male, and 318 (55\%) were female. The participants ranged from 18 to 55 years and above, with most in the age group between 18-25 (56\%), followed by the $26-35$ group (26\%), by $36-55$ group (12\%), and finally those over 55 (4\%). Almost 48 per cent of the respondents had some college education. Over 65 per cent of respondents earned less than $\$ 40,000$ a year, indicative that service employees are relatively poorly paid. The respondents occupied a variety of positions including bar tenders, bellman, cashier, concierge, front desk agent, server, and sales representative. About one-third of the respondents had been employed by their current organization for three to five years, with 5\% having more than 20 years of experience.

\section{Measures}

EL Since the present study involved a survey of hospitality organisations, the research used the Hospitality Emotional Labor Scale (HELS) first developed by Chu and 
Murrmann (2006). This scale was developed specifically to measure the EL presentation of hospitality employees and consists of three factors: surface acting, genuine acting and deep acting. To ensure that the present investigation was consistent with the original acting strategies within the EL concept, a decision was made to exclude the two items that had been developed to measure genuine acting.

Useful items for measuring surface acting include: "I fake the emotions I show when dealing with customers"; “my interactions with customers are very robotic”. In the case of deep acting, the sample items are "I work at calling up the feelings I need to show to customers"; "I try to change my actual feelings to match those that I must express to customers”. Values were based on a seven-point Likert-type scale with responses ranging from " 1 ” (strongly disagree) to “7” (strongly agree). Due to the omission of one of the factors from the original HELS, confirmatory factor analysis (CFA) was performed with a view to confirming the factor structure.

Performance For the purposes of the present study, the measurement of performance included both task performance and OCBs, and used a seven-item in-rolebehaviours scale. Three of the seven items were developed by O’Reilly and Chatman (1986). Four items drawn from Williams and Anderson were provided with a view to achieving consistency with the definition of task performance, namely behaviours associated with formal reward systems which are embedded in relevant job descriptions. This measure was assessed using self-reporting.

The accumulated empirical evidence suggests that evaluations of performance that use employee self-reporting offer good validity, with a less restricted range and fewer errors than objective measures, especially when the insights are gathered anonymously (Churchill et al., 1985; Schneider at al., 1996; Singh, 2000). The questions were measured using a seven- 
point Likert scale, with 1 = strongly disagree, and 7 = strongly agree. The Cronbach Alpha coefficient for the seven-item task performance scale was .86.

The scale developed by Podsakoff, MacKenzie, Moorman, and Fetter (1990) was used to measure OCBs. It was based around Organ’s (1988) five facets namely altruism, conscientiousness, sportsmanship, courtesy and civic virtue. Altruism may be viewed as a discretionary behaviour and involves providing assistance with an organizationally relevant task or problem to another person. Conscientiousness involves discretionary employee behaviours which exceed minimum role requirements. These include behaviours such as attendance, obeying rules and regulations, and taking breaks; sportsmanship which may be interpreted as the willingness of employees to tolerate less than ideal circumstances without complaining; courtesy as discretionary behaviour aimed at preventing the occurrence of work-related problems with others; and civic virtue as behaviour indicating that he/she participates in, is involved in, or is concerned about the life of the company in a responsible manner (see Podsakoff et al., 1990, p115).

Although the dimensions are comprehensive, a meta-analysis conducted by LePine, Erez and Johnson (2002) revealed strong correlations among the five dimensions and equivalent relationships with identified predictors. This raises concerns about the existing dimensions of OCB. In view of such inconsistencies, the researchers performed CFA for the purposes of the present scale. The results are reported in the next section of the paper.

Burnout To measure participant burnout the researchers used the Maslach Burnout Inventory (MBI) (Maslach \& Jackson, 1986). The inventory is a scale consisting of three dimensions, namely emotional exhaustion (9 items), diminished personal accomplishment (7 items), and depersonalisation (6 items). In the case of emotional exhaustion the sample item that was provided is "I feel emotionally drained from my work"; for diminished personal accomplishment “I can’t deal effectively with the problems of my recipients”; and for 
depersonalisation; “I have become more callous towards people since I took this job,” Although originally designed for service workers, the MBI has been applied to other occupations including computer professionals and police officers (see Brotheridge \& Grandey, 2002).The MBI is the most commonly used scale to measure burnout and has been validated by Cordes and Dougherty (1993). In the present study the items were assessed using a seven-point Likert scale ( 1 = strongly disagree, 7 = strongly agree) to indicate the extent of participant agreement with the statement. The applicable Cronbach Alpha coefficients for the three dimensions were .93 in the case of emotional exhaustion, .86 for diminished personal accomplishment, and .82 for depersonalisation.

Emotional intelligence In order to estimate emotional intelligence, the present study used the self-report EI Test (SREIT) designed by Schutte et al. (1998), which was based on Salovey and Mayer’s ability model (1990). The 33-item self-report measure includes items such as "By looking at their facial expression, I recognize the emotions people are experiencing” and “I easily recognize my emotions as I experience them.” According to Schutte et al. (1998), the relevant scale generates correlations with theoretically related constructs such as alexithymia, attention to feelings, clarity of feelings, mood repair, optimism and impulse control.

The scale exhibited good internal consistency and test-retest reliability, predictive validity, and discriminant validity with strong results for each analysis (Schutte et al., 1998). These positive attributes played an important part in determining the inclusion of the selection. Data were collected on a seven-point Likert scale, with $1=$ strongly disagree and 7 $=$ strongly agree. These labels indicate alignment between the items and the views expressed by respondents. Higher total scores are reflective of greater self-reported emotional intelligence. A factor analysis of the 33-items resulted in one factor representing each of the categories: appraisal and expression of emotion in the self and others, regulation of emotion 
in the self and others and utilization of emotions in solving problems (Schutt et al., 1998). Petrides and Furnham (2000) have advocated for a four-factor structure for SREIT. However, the sub-dimensions obtained from CFA in other studies were unstable, and one of the factors had a low Cronbach alpha value (below .70).It is appropriate to perform CFA in the light of inconsistencies within this scale dimensionality. The results and applicable Cronbach Alpha coefficient are reported in the next section of the paper.

Occupational commitment An 18-item occupational commitment scale that had been developed by Meyer, Allen and Smith (1993) was used in this study. The scale is the most frequently cited of its type within the literature, and good validities and reliabilities have been reported (Blau, 2003; Meyer, Allen \& Smith, 1993). In the case of affective occupational commitment the proposed sample item is "I am enthusiastic about my current occupation”. Items that may be applied for continual occupational commitment are "changing occupations now would be difficult for me to do" and "it would be costly for me to change my occupation now”. Equivalent sample items for normative commitment include: “I would feel guilty if I left my occupation” and "I feel a responsibility to the current occupation to continue in it”. A seven-point Likert scale was used to measure the two scales and to indicate respondent conformity with the statement attributable to each item, with 1 = strongly disagree, 7 = strongly agree. In the present study, the applicable Cronbach Alpha coefficients for the three commitments were $.81, .89$, and .78 respectively.

\section{Procedure}

A self-report questionnaire was developed to collect information using a paper-pencil test. The questions investigated EL, burnout, emotional intelligence, affective occupational commitment, task performance and OCB. The written instructions assured respondents of anonymity. The survey packets included a cover letter introducing the research and explaining its significance and objectives. An expression of thanks was also provided to 
prospective respondents along with a consent form, a questionnaire, and a pre-paid envelope. Detailed instructions were included to stimulate and guide participation. Research assistants distributed the questionnaire to prospective respondents who were required to respond within two months of receipt.

\section{Analyses and results}

\section{Factor analyses for HELS, SREIT and OCB}

CFA was conducted for the HELS, SREIT and OCB scales with a view to assessing their dimensionalities. The CFA analyses were based on a Pearson Covariance matrix and Maximum Likelihood Estimation (MLE). Following Hu and Bentler’s (1999) suggestion, two absolute close-fit indices (SRMR and RMSEA) and two incremental close-fit indices were chosen (TLI and CFI) to evaluate model fit, with SRMR and RMSEA $<.06$ and TLI and CFI $>.95$ considered as being well fitted. The results arising from performing CFA for HELS confirmed the two-factor structure as a good model fit $\left(\chi^{2}(561)=217.32, p<.0005\right.$, SRMR $=.05$ and $\mathrm{RMSEA}=.05$, CFI $=.96$ and TLI $=.95)$. As indicated in Table 1 , this item has a significant loading on the corresponding factor.

Insert Table 1 about here

In light of the inconsistent results generated by previous research, the researchers used exploratory factor analysis (EFA) to identify the factor structures prior to undertaking CFA for SREIT and OCB. The results of the factor analysis for SREIT produced a four-factor structure in the component matrix. However, the other three factors have cross loadings with the first factor, and each loaded only with a single item. Conduct of Cattell's Scree test indicated that the single factor solution was appropriate, consistent with Schutte et al's (1998) findings. An identical process was performed to identify the OCB scale. 
The conduct of component matrix and Cattell's Scree test confirmed the appropriateness of retaining a single factor. The results that were obtained from performing CFA also supported the one-factor solution for the two scales, with reasonable model fit indices for SREIT: $\chi^{2}(571)=1762.34, \mathrm{p}<.0005, \mathrm{SRMR}=.04$ and $\mathrm{RMSEA}=.05, \mathrm{CFI}=.98$ and TLI $=.95$, and for OCB: $\chi^{2}(569)=1379.45, \mathrm{p}<.0005, \mathrm{SRMR}=.05$ and $\mathrm{RMSEA}=.04$, $\mathrm{CFI}=.97$ and TLI $=.96$. Less optimal results were obtained from the four-factor solution for SREIT and five-factor structure for OCB. On this basis, the current researchers adopted the single-factor SREIT and OCB. The Cronbach coefficients for SREIT and OCB were .95 and .93 respectively.

Table 2 provides a summary of the study variables, means, standard deviations, intercorrelations and Cronbach Alpha coefficients. The results show that surface acting is unrelated to deep acting, reflective of the mutual exclusivity of the two acting strategies. Interestingly, only surface acting is significantly related to performance outcome, particularly task performance. Both acting strategies are strongly related to the three dimensions in the case of burnout. All of the scales demonstrated good internal consistency reliability, where .70 is the minimum alpha acceptable (Nunnally \& Bernstein, 1994).

Insert Table 2 about here

\section{Measurement validity and structural model}

Structural equation modelling was conducted to test the propositions. The construct validities were tested prior to testing the proposed relationships between the variables following the two-step approach suggested by Anderson and Gerbing (1988). Because every construct in this study was measured using multiple items, including all indicators within the testing would add excessive complexity for making accurate estimations. Following the 
approach recommended by Park and Holloway (2003), the items for each construct were summed into a single indicator measure. The results of the squared multiple coefficient values appear in Table 2 and indicate that all items have significant loadings on their corresponding constructs.

On the basis of what has been reported, the convergent validities were supported. For purposes of discriminant validity, Fornell and Larcker's (1981) approach was used and a comparison was made between the average variance extracted (AVE) of each construct and shared variance between the study variables (see Farrell, 2009). According to Fornell and Larcker, discriminant validity is supported if the AVE for each construct is greater than its shared variance with any other construct. The researchers squared the correlations between every two constructs and obtained the shared variance against the AVE averages. The results that are displayed in Table 3 indicate that discriminant validity was established.

Insert Table 3 about here

To test the propositions, the information that arose from the assessment of measurement validity was used to estimate the overall structural model. The errors for each construct were set at .85 (see Williams \& Podsakoff, 1989). The proposed main effect model was estimated with a view to examining the structural relationships. The interaction terms were used for testing the moderating effects of emotional intelligence and occupational commitment. Lance’s (1988) residual centring approach was adopted with a view to obtaining interaction terms for surface or deep acting.

Emotional intelligence or a combination of three-facet occupational commitment was achieved by partialling out the influence of main effects. These interaction terms were then included in the path analysis. The overall goodness-of-fit statistics suggest that the proposed 
model is acceptable with CFI and TLI values around .95, and SRMR and RMSEA values below .06.

Table 4 displays the results for H1. Specifically it was found that surface acting exerted a significant positive influence on both task performance $(\beta=.14, \mathrm{p}<.001)$ and OCB $(\beta=.09, \mathrm{p}<.05)$. However, deep acting appeared to have no significant relationship with either dimension of the performance outcome. As for the relationships between EL and burnout in $\mathrm{H} 3$, the results show that both surface acting and deep acting had significant effects on three dimensions of burnout: the beta values for surface/deep acting - emotional exhaustion are $.39(\mathrm{p}<.0005)$ and $.08(\mathrm{p}<.05), .11(\mathrm{p}<.05)$ and $.12(\mathrm{p}<.0005)$ for surface/deep acting - diminished personal accomplishment, and .37 ( $<$.0005) and .14 (p < .005) for surface/deep acting - depersonalisation. These results support H3.

Insert Table 4 about here

The analyses of the moderating effects of occupational commitment and emotional intelligence generated mixed results (Table 5). The results indicate that the moderating effects of affective occupational commitment occurred primarily between surface acting and performance outcome, whereas normative and continuance occupational commitments had no effects in the relationship between EL and the criterion variable. The effect of affective occupational commitment for surface acting - task performance is .18, $(\mathrm{p}<.0005)$, for surface acting - OCB is .16, $(\mathrm{p}<.0005)$, and for deep acting - OCB is .07 ( $<<.05)$. These relationships are shown in Figure $2-5$.

Testing emotional intelligence as a moderator of EL in burnout shows that it significantly reduced the levels of surface/deep acting - emotional exhaustion $(\beta=-.36, p<$ $.0005 ; \beta=-.18, \mathrm{p}<.05)$, surface/deep acting - diminished personal achievement $(\beta=-.16, \mathrm{p}$ 
$<.0005 ; \beta=-.09, \mathrm{p}<.05)$, surface/deep acting - depersonalisation $(\beta=-.19, \mathrm{p}<.0005 ; \beta=-$ $.19, \mathrm{p}<.0005)$. The moderating effects are demonstrated in Figure $6-11$.

Insert Table 5 and Figures 2 - 11 about here

\section{Discussion}

This study examines the relationships between EL, performance (task performance and OCBs), and burnout. Occupational commitment and emotional intelligence were proposed as potential moderators in EL strategy. The study addresses a research gap and enriches the EL literature by thoroughly analysing its relationship with job performance and incorporating occupational commitment and emotional intelligence as facilitators of the EL process.

Whilst the conduct of structural equation modelling generated some interesting results, not all were consistent with the various hypotheses. In summary, surface acting demonstrated significant influence on both task performance and OCBs, whereas deep acting was not associated with performance outcomes. Consistent with Hypothesis 3, surface and deep acting both had a strong association with all dimensions of burnout.

The testing of moderation has shown that emotional intelligence reduced all three dimensions of burnout through surface or deep acting. Among the three facets of occupational commitment, the results show that affective occupational commitment enhanced employee performance and reduced the level of burnout when engaging in surface acting. In the case of the present study, continuance and normative occupational commitment did not significantly moderate the relationship between EL and the criterion variables, though the former improved task performance as a result of surface acting. The following section discusses these findings. 


\section{EL and performance outcomes}

From this study it is evident that there is a significant association between surface acting and task performance. Where employees regulate their emotional expressions on the basis of organizational display rules (surface acting), following the rules of acting may help the accomplishment of required duties (task performance). Such behaviour does not need to represent real feelings. In the case of frontline hospitality employees generally, and those working in restaurants and hotels in particular, customer encounters are often short and temporary; acting superficially is more spontaneous and thus facilitates the timely accomplishment of tasks. Although OCBs are not required by most organisations, such behaviours may become habitual or be undertaken for the sake of making a positive impression. Since surface acting is the "act” required by the organisation it may become habitual in the longer run, and performing OCB may be part of habitual behaviour. Interestingly, deep acting is not strongly associated with performance outcomes. Although appearing to contradict the findings of prior research, this outcome may be attributable to the relatively low wages earned by respondents. As stated in the previous section, most of the survey participants earned less than $\$ 40,000$. Since deep acting requires a great "acting” effort, employees may avoid the necessity to "act” deeply when a less onerous approach (surface acting) can accomplish the task.

\section{EL and burnout}

As proposed, surface and deep acting relate positively to all three dimensions of burnout. Although some studies have reported that only surface acting is related to burnout, the finding of the present study has supported Ashforth and Humphrey’s (1993) proposition and the findings of Mikolajczak et al.'s (2007) study. The inconsistency may have arisen as a result of different sampling frames. Given the intensifying competition and organizational restructuring which has affected the hospitality industry in recent years, service employees 
face the threat of retrenchment as well as excessive job demands (see Lo \& Lamm, 2005). To retain their jobs, they may feel obliged to follow organizational rules to "act.” Lack of spontaneity and unwillingness in their acting may eventually lead to job dissatisfaction and burnout (Brotheridge \& Grandey, 2002; Pugliesi, 1999). If these employees perceive that it is necessary to act genuinely (deep acting) but are unable or unwilling to do so (due to low wages), they may suffer low self-esteem or self-alienation, leading ultimately to burnout.

The current study provides new insights into deep acting strategies and suggests that researchers should be cautious about promoting deep acting. This finding is consistent with Ashforth and Humphrey’s argument that EL is dysfunctional and that “deep acting may ultimately lead to self-alienation ... the masking or reworking of authentic emotions that one would otherwise prefer to express has been linked to psychological and physical dysfunctions (see Ashforth \& Humphrey, 1993, p 97).

\section{The Moderating influence of occupational commitment and emotional}

\section{intelligence}

The results from the moderation analyses indicate that the incorporation of moderators can be a remedy for enhancing EL-related performance outcomes and for reducing EL-caused burnout. The incorporation of occupational commitment as a moderator of EL has enhanced both task performance and OCBs, and reduced the likelihood of burnout, particularly in the case of surface acting. This finding conforms to social identity theory, which suggests that those who identify strongly with their organizational or occupational role tend to conform to role expectations, including display rules.

Compliance with display rules is associated positively with performance (Ashforth \& Humphrey, 1993). Affective occupational commitment is defined as affective attachment to one’s occupation (Meyer et al., 1993). This attachment may lead to the identification of one's belief with the applicable occupation. Identity motivates the person to follow the stereotype 
when acting or behaving. Such motivations prevent the employee from feeling emotionally exhausted, thus enhancing the sense of personal achievement. An introverted person who occupies a frontline position may for example act in an extrovert manner because it is perceived as a stereotypical requirement for such positions and as a prerequisite for good performance. It may be possible for an introvert to learn extrovert surface acting behaviours. This outcome indicates that occupational commitment is a successful moderator of surface acting but that such influence is not conveyed in the case of deep acting since the latter involves greater effort. Lowly paid hospitality employees may not perceive this as necessary. The finding that continual occupational commitment improves task performance through surface acting indicates that hospitality employees strive to perform their duties effectively for the sake of continuity of employment. The absence of moderating effects from normative occupational commitment may be construed as meaning that such commitment is not genuine or conscientious because respondents did not perceive the necessity of being obliged to their occupation.

Emotional intelligence moderates the relationship between the two EL acting processes and burnout. This finding is consistent with the Daus and Ashkanansy (2005) assertion that emotional intelligence plays a significant role in jobs which demand high EL such as customer service representative. Service encounters between employees and customers often involve a strong emotional component due to unpredictable situational factors and the need to deal with demanding customers (see Ashforth \& Humphrey, 1993). Employee emotional intelligence may facilitate service transactions by facilitating the management of one's own emotions and those of others. Smooth transactions lead to fewer customer complaints and consequently to low employee stress which is a precursor of burnout. 
This study contributes to the EL and emotional intelligence literature. Firstly, the finding that there is a positive relationship between deep acting and burnout should alert EL researchers to the need for a deeper understanding of genuine acting or for a reassessment of its consequences. Equally, researchers should consider the study population as a possible cause of inconsistent findings. Future studies should test this relationship in different contexts with a view to verifying the findings.

Secondly, the significant moderating effect exhibited by emotional intelligence in the EL-burnout relationship supports Grandey’s (2000) proposition and extends its moderation role into the EL process. Third, the successful incorporation of occupational commitment into the moderation model used in the present investigation has confirmed Ashforth and Humphrey’s (1993) proposition on social identity theory and has enriched the literature on EL.

The use of a one-factor solution for the OCB and emotional intelligence measures in this study has resulted in better model fit indices when undertaking CFA. The result of unidimensional OCB was consistent with the conclusions reached by LePine et al. (2002). The result of the single-factor emotional intelligence also conforms to Schutte et al.'s (1998) study. The findings are a reminder to researchers about the importance of conducting factor analysis of these measures before undertaking further analysis.

\section{Managerial implications}

The present study demonstrates the capacity of emotional intelligence to reduce the incidence of burnout that is associated with acting. Since training and development can provide effective means of enhancing activity (see Boyatzis, Cowan \& Kolb, 1995; Slaski \& Cartwright, 2002), relevant training should be provided for existing frontline employees, particularly in the case of those who perform emotional labor but are unable to act appropriately. It is evident that higher levels of emotional intelligence can reduce the 
likelihood of burnout and may improve performance. Emotional intelligence testing can also be used for the purposes of recruitment and selection. The conduct of such testing could help human resource managers to identify suitable candidates.

The finding that occupational commitment enhances performance outcomes indicates that human resource practitioners and managers should examine the factors that influence such commitment. Service employee performance has implications for customer satisfaction and loyalty, leading ultimately to profitability. Identifying the level of commitment amongst frontline employees for their positions might facilitate the management of customer relations. Although few prior studies have investigated its antecedents, the significant correlation that researchers have identified between occupational and organizational commitments and antecedents such as job satisfaction, organizational culture and leadership style can provide some guidance for practitioners (see Allen \& Meyer, 1990; Cohen, 1992; 2007). Cohen (2007) contributes a comprehensive explanation of the interrelationship between the two commitments. To enhance employee occupational commitment, management would be well served to look first into factors that affect organizational commitment, such as making adjustments to organizational culture and leadership. Employees who identify themselves with the organization are more likely to remain in a given occupation or role. The identification of these factors on the basis of social identity theory provides guidance for human resource practitioners when seeking out the right people for positions.

\section{Limitation and future research}

The findings of the present study are applicable to frontline hospitality employees. Ideally a wider sample frame could have strengthened the generalizability of the findings to other service sectors. Secondly, the use of self-rated performance was not ideal. Previous uses of this approach have been the subject of both criticism and stout defence within the 
literature (e.g. Churchill, Ford, Hartley \& Walker, 1985). However anonymous responses may add credibility to the accuracy of the performance ratings.

In acknowledging the limitations of the study, it is noted that obtaining supervisor/peer-rating or objective performance outcomes through random sampling was impractical. Future studies could endeavour to obtain other-performance-ratings with a view to extending the generalizability of the findings. 


\section{References}

Allen, Natalie J., \& Meyer, John. P. (1990). The measurement and antecedents of affective, continuance and normative commitment to the organization. Journal of Occupational Psychology, 63(1), 1-18.

Anderson, James C.;Gerbing, David W. (1988). Structural equation modeling in practice: A review and recommended two-step approach. Psychological Bulletin, Vol 103(3), 411-423. doi: $\underline{10.1037 / 0033-2909.103 .3 .411}$

Ashforth, Blake E., \& Humphrey, Ronald. H. (1993). Emotional Labor in Service Roles: The Influence of Identity. Academy of Management Review, 18(1), 88-115.

Ashkanasy, Neal M, Ashton-James, E. \& Jordan, J. 2004, 'Performance impacts of appraisal and coping with stress in the workplace settings: The role of affect and emotional intelligence’, in PL Perrewe \& DC Ganster (eds.), Emotional and Psychological Processesand Positive Intervention Strategies, vol. 3, pp. 1-43.

Beck, Karen, \& Wilson, Carlene (2000). Development of affective organizational commitment: A cross-sequential examination of change with tenure. Journal of Vocational Behavior. 56(1). 114-136

Borman, Water C., \& Motowidlo, Stephan. J. (1997). Task Performance and Contextual Performance: The Meaning for Personnel Selection Research., Human Performance (Vol. 10, pp. 99): Lawrence Erlbaum Associates.

Boyatzis, Richard E., Cowen, Scott S., \& Kolb, David. A. (1995). Innovation in professional education: Steps on a journey from teaching to learning: Jossey-Bass.

Brotheridge, Celeste. M. (2006). The role of emotional intelligence and other individual difference variables in predicting emotional labor relative to situational demands. Psicothema, 18(Sup), 139-144. 
Brotheridge, Celeste. M., \& Grandey, Alicia A. (2002). Emotional Labor and Burnout: Comparing Two Perspectives of. Journal of Vocational Behavior, 60(1), 17-39.

Carmeli, Abraham, \& Josman, Zvi E. (2006). The relationship among emotional intelligence, task performance, and organizational citizenship behaviors. Human Performance, 19(4), 403-419.

Cherniss, Cary (1993). Role of professional self-efficacy in the etiology and amelioration of burnout: research on job burnout. Academy of Management Review, 18(4), 621-656.

Churchill, Gilbert. A., Ford, Neil. M., Hartley, Steven W., \& Walker, Orville C. (1985). The determinants of salesperson performance: A meta-analysis. Journal of Marketing Research, 22(2), 103-118

Cohen, Aaron (1991). Career stage as a moderator of the relationships between organizational commitment and its outcomes: A meta-analysis. Journal of Occupational Psychology, 64, 253-268.

Cohen, Aaron, (1992). Antecedents of organizational commitment across occupational groups: A meta-analysis. Journal of Organizational Behaviour. 13(6): 539-558

Cohen, Aaron (2007). Dynamics between occupational and organizational commitment in the context of flexible labor markets: a review of literature and suggestions for a future research agenda. Working paper. March 2007.

Cordes, Cynthia L., \& Dougherty, Thomas W. (1993). A review and an integration of research on burnout. Academy of Management review, 18, 621-56

Chang, Eunmi (1999). Career Commitment as a Complex Moderator of Organizational Commitment and Turnover Intention. Human relations. 52(10): 1257-1278

Dahlin, M., Joneborg, N. \& Runeson, B (2007). Performance-based self-esteem and burnout in a cross-sectional study of medical students. Medical Teacher. 29(1). 43-48 
Daus, Catherine. S., \& Ashkanasy, Neal. M. (2005). The Case for the Ability-Based Model of Emotional Intelligence in Organizational Behaviour. Journal of Organizational Behaviour, 26, 453-466.

Douglas, C., Frink, D., \& Ferris, R. (2004). Emotional intelligence as a moderator of the conscientiousness-performance relationship. Journal of Leadership \& Organizational Studies. 10, 2-13.

Erickson, Rebecca J., \& Ritter, Christian. (2001). Emotional labor, burnout, and inauthenticity: does gender matter? Social Psychology Quarterly, 64(2), 146-163.

Farrell, Patricia (2009). Investing in staff for student retention. The NEA 2009 Alamanac of High Education, 85-92

Fineman, Stephen (1993). Organizations as emotional arenas. Emotions in Organisations. Thousand Oaks, CA, USA: Sage Publications. IncFineman, Stephen (Ed). Xiii, 230pp

Firth Hugh \& Britton, Peter (1989). “Burnout”, absence and turnover amongst British nursing staff. Journal of Occupational Psychology. 62(1). 55-59

Fornell Claes \& Larcker David (1981). Structural equation models with unobservable variables and measurement error: algebra and statistics. Journal of Marketing Research. 18(3). 382-388.

Gabbott M., Tsarenko, Y. and Mok, W. H. (2011). Emotional intelligence as a moderator of coping strategies and service outcomes in circumstances of service failure. Journal of Service Research. 14(2), 234-248

Grandey, Alicia A. (2003). When" the show must go on": Surface acting and deep acting as determinants of emotional exhaustion and peer-rated service delivery. Academy of Management Journal, 46(1), 86-96.

Hartline, Michael D. and Ferrell. O.C. (1993). Service Quality Implementation: The Effects of Organizational Socialization and Managerial Actions on Customer-Contact 
Employee Behaviors. MSI report, technical working paper, report \# 93-122, December.

Hochschild, Arlie R. (1983). The managed heart: University of California Press Berkeley, CA.

Houkes, Inge, Janssen, Peter. P. M., de Jonge, Jan, \& Nijhuis, F. J. N. (2001). Specific relationships between work characteristics and intrinsic work motivation, burnout and turnover intention. European Journal of Work and Organizational Psychology, 10, 123.

Johnson, Hazel-Ann. M., \& Spector, Paul. E. (2007). Service with a smile: Do emotional intelligence, gender, and autonomy moderate the emotional labor process? Journal of Occupational Health Psychology, 12(4), 319.

Jordan, PJ, Ashkanasy, NM \& Härtel, CEJ 2003, ’The case for emotional intelligence in organizational research’, Academy of Management Review, 28 (2), 195-197.

Judd, Charles M.;Kenny, David A.;McClelland, Gary H. (2001). Estimating and testing mediation and moderation in within-subject designs. Psychological Methods, Vol 6(2), Jun 2001, 115-134. doi: 10.1037/1082-989X.6.2.115

Kim, Hyun Jeong \& Agrusa, Jerome (2011). Hospitality service employees’ coping styles” the role of emotional intelligence, two basic personality traits, and socio-demographic factors. International Journal of Hospitality Management. 30(3). 588-598

Kim, Hyun Jung (2008). Hotel service providers' emotional labor: The antecedents and effects on burnout. International Journal of Hospitality Management, 27(2), 151-161.

Lance, Charls. E., 1988. Residual centering, exploratory and confirmatory moderator analysis, and decomposition of effects in path models containing interactions. Applied Psychological Measurement, 12 (June), 163-75. 
Lee, Raymond T., \& Ashforth, Blake E. (1996). A Meta-Analytic Examination of the Correlates of the Three Dimensions of Job Burnout. Journal of Applied Psychology, 81(2), 123-133.

Leiter, Michael P., \& Maslach, Christina (1988). The impact of interpersonal environment on burnout and organizational commitment. Journal of Organizational Behavior, 9(4), 297-308.

LePine, Jeffrey. A., Erez, Amir, \& Johnson, Diane E. (2002). The nature and dimensionality of organizational citizenship behavior: A critical review and meta-analysis. Journal of Applied Psychology, 87(1), 52-65.

Levine, Ross (1997). Financial development and economic growth: views and agenda. Journal of economic literature, 35(2), 688-726.

Lo Karen \& Lamm, Felicity (2005). Occupational stress in the hospitality industry - an employment relations perspective. Hospitality Stress. http://library.auckland.ac.nz/subject-guides/bus/docs/loandlamm.pdf

Mann, Sandi, \& Cowburn, J. (2005). Emotional labor and stress within mental health nursing. Journal of Psychiatric and Mental Health Nursing, 12(2), 154-162.

Maslach, Christina \& Jackson, Susan. (1986). Maslach burnout inventory. Evaluating Stress a book of resources, 31, 191-218.

Maslach, Christian, Schaufeli, WilmarB. \& Leiter, Michael P. (2001). Job burnout. Annual Review of Psychology, 52, 397_422.

Mayer, John D., \& Salovey, Peter (1997). What is emotional intelligence? In P. Salovey \& D. Sluyter (Eds.), Emotional development and emotional intelligence: Implications for educators (pp. 3-31). New York: Basic.

Mayer, John D., Salovey, Peter., Caruso, David R., \& Sitarenios, G. (2001). Emotional intelligence as a standard intelligence. 
Meyer, John. Peter, Allen, N. J., \& Smith, C. A. (1993). Commitment to organizations and occupations: Extension and test of a three-component conceptualization. Journal of Applied Psychology, 78(4), 538.

Meyer, J. P., Allen, N. J., \& Smith, Catherine A. (1993). Commitment to organizations and occupations: Extension and test of a three-component conceptualization. Journal of Applied Psychology, 78(4), 538.

Mikolajczak, Moira, Menil, Clemeentine Luminet, Olivier (2007). Explaining the protective effect of trait emotional intelligence regarding occupational stress: exploration of emotional labor process. Journal of Research in Personality. 41(2007), 1107-1117

Miller, Katherine I., \& Koesten, Joy (2008). Financial feeling: An investigation of emotion and communication in the workplace. Journal of Applied Communication Research, 36(1), 8-32.

Montgomery, Anthony J., Panagopolou, Efharis, de Wildt, Martijn, \& Meenks, Ellis (2006). Work-family interference, emotional labor and burnout. Journal of Managerial Psychology, 21(1), 36-51.

Nunnally, J. C., \& Bernstein, I. H. Psychometric theory. 1994. McGraw, New York.

O'Reilly, Charles. A., \& Chatman, Jennifer (1986). Organizational commitment and psychological attachment: The effects of compliance, identification, and internalization on prosocial behavior. Journal of Applied Psychology, 71(3), 492.

Organ, Dennis W. (1988). Organizational citizenship behavior: The good soldier syndrome: Lexington Books/DC Heath and Com.

Park, Jeong-Eun \& Holloway, Betsy B. (2003). Adaptive selling behaviour revisited: an empirical examination of learning orientation, sales performance, and job satisfaction. Journal of Personal Selling \& Sales Management. XXIII (3). 239-251 
Parkinson, B. (1991). Emotional stylists: strategies of expressive management among trainee hairdressers. Cognition and Emotion, 5:419-434

Petrides, K., \& Furnham, Adrian. (2000). On the dimensional structure of emotional intelligence. Personality and Individual Differences, 29(2), 313-320.

Petrides, K., \& Furnham, Adrian. (2003). Trait emotional intelligence: Behavioural validation in two studies of emotion recognition and reactivity to mood induction. European Journal of Personality, 17(1), 39-57.

Pienaar Jacobus \& Willemse, Sharron (2008). Burnout, engagement, coping and general health of service employees in the hospitality industry. Tourism Management. 29(6)/ 1053-1063

Podsakoff, Philip M., MacKenzie, Scott. B., Moorman, Robert H., \& Fetter, Richard (1990). Transformational leader behaviors and their effects on trust, satisfaction, and organizational citizenship behaviors. Leadership Quarterly, 1(2), 107-142.

Prentice C \& King B (2011). Emotional intelligence and the service performance of casino frontline employees. Tourism and Hospitality Research. Vol 11 (1). DOI:10.1057/thr.2010.21

Pugliesi, Karen (1999). The consequences of emotional labor: Effects on work stress, job satisfaction, and well-being. Motivation and Emotion, 23(2), 125-154.

Riveros, Andrea M. M \& Tsai, Shir-Tau. T.(2011). Career commitment and organizational commitment in for-profit and non-profit sectors. International Journal of Emerging Sciences, 1(3), 324-340

Rousseau, Denise. M. (1995). Psychological contracts in organizations: Understanding written and unwritten agreements: SAGE Publications, Inc.

Rutter, D. R. \& Fielding, P.J. (1988). Sources of occupational stress: an examination of British prison officers. Work \& Stress, 2:291-299 
Sakiyama, Yukinori, \& Graves, David B. (2009). Neutral gas flow and ring-shaped emission profile in non-thermal RF-excited plasma needle discharge at atmospheric pressure. Plasma Sources Science and Technology, 18, 025022.

Salami, Samuel O. (2007). Moderating Effect of Emotional Intelligence on the Relationship Between Emotional Labor and Organizational Citizenship Behaviour. European Journal of Social Sciences. 5(2), 142-150

Schutte, Nicola. S., Malouff, John. M., Hall, Lena. E., Haggerty, Donald J., Cooper, Joan T., Golden, Charles J., \& Dornheim, Liane (1998). Development and validation of a measure of emotional intelligence. Personality and Individual Differences, 25(2), 167-177.

Seeman, Nadrian C. (1991). Construction of three-dimensional stick figures from branched DNA. DNA and cell biology, 10(7), 475-486.

Singh, Jagdip (2000). Performance productivity and quality of frontline employees in service organisations. Journal of Marketing. 64(April). 15-34

Singh, Jagdip, Goolsby, Jerry, R. \& Rhoads, Gary K. (1994). Behavioural and psychological consequences of boundary spanning burnout for customer service representative. Journal of Marketing Research. 31(4). 558-569.

Slaski, Mark, \& Cartwright, Susan (2002). Health, performance and emotional intelligence: an exploratory study of retail managers. Stress and Health, 18(2), 63-68.

Smith, C. Ann, Organ, Dennis W., \& Near, Janet. P. (1983). Organizational citizenship behavior: Its nature and antecedents. Journal of Applied Psychology, 68(4), 653.

Stevens, B. (1998). Composite measures of pain. Progress in pain research and management, $10,161-178$. 
Suh, Taewon, Houston, Mark B. Barney, Steven, M \& Kwon, Ik-Whan, G. (2010). The impact of mission fulfilment on the internal audience: psychological job outcomes in a services setting. Journal of Service Research. 14(1), 76-92.

Suliman, Abubakr M., \& Iles, Paul A. (2000). The multi-dimensional nature of organizational commitment in a non-western context. Journal of Management Development, 19(1), 71-83.

Surana, Shilpa, \& Singh, Anup K. (2009). Development and validation of job burnout scale in the Indian context. International Journal of Society Systems Science, 1(4), 351-374.

Tabachnick, Barbara, \& Fidell, Linda (2007). Using multivariate analysis. Using multivariate analysis.

Testa, M.R., (2001). Organizational commitment, job satisfaction, and effort in the service environment. The Journal of Psychology, 135(2): 226-236.

Williams, Larry J., \& Anderson, Stella E. (1991). Job satisfaction and organizational commitment as predictors of organizational citizenship and in-role behaviors. Journal of Management, 17(3), 601.

Zeithaml, V. A., Berry, L. L., \& Parasuraman, A. (1996). The behavioral consequences of service quality. Journal of Marketing, 60(2), 31-46

Witt, L. A. (1993). Reactions to work assignment as predictors of organizational commitment: the moderating effect of occupational identification. Journal of Business Research. 26(1), 17-30.

Hartel, C. J., Barker, S. \& Baker, N.J. (1999). The role of emotional intelligence in service encounters: a model of predicting the effects of employee-customer interactions on consumer attitudes, intentions, and behaviours. Australian Journal of Communication. 26(2), 77-87 


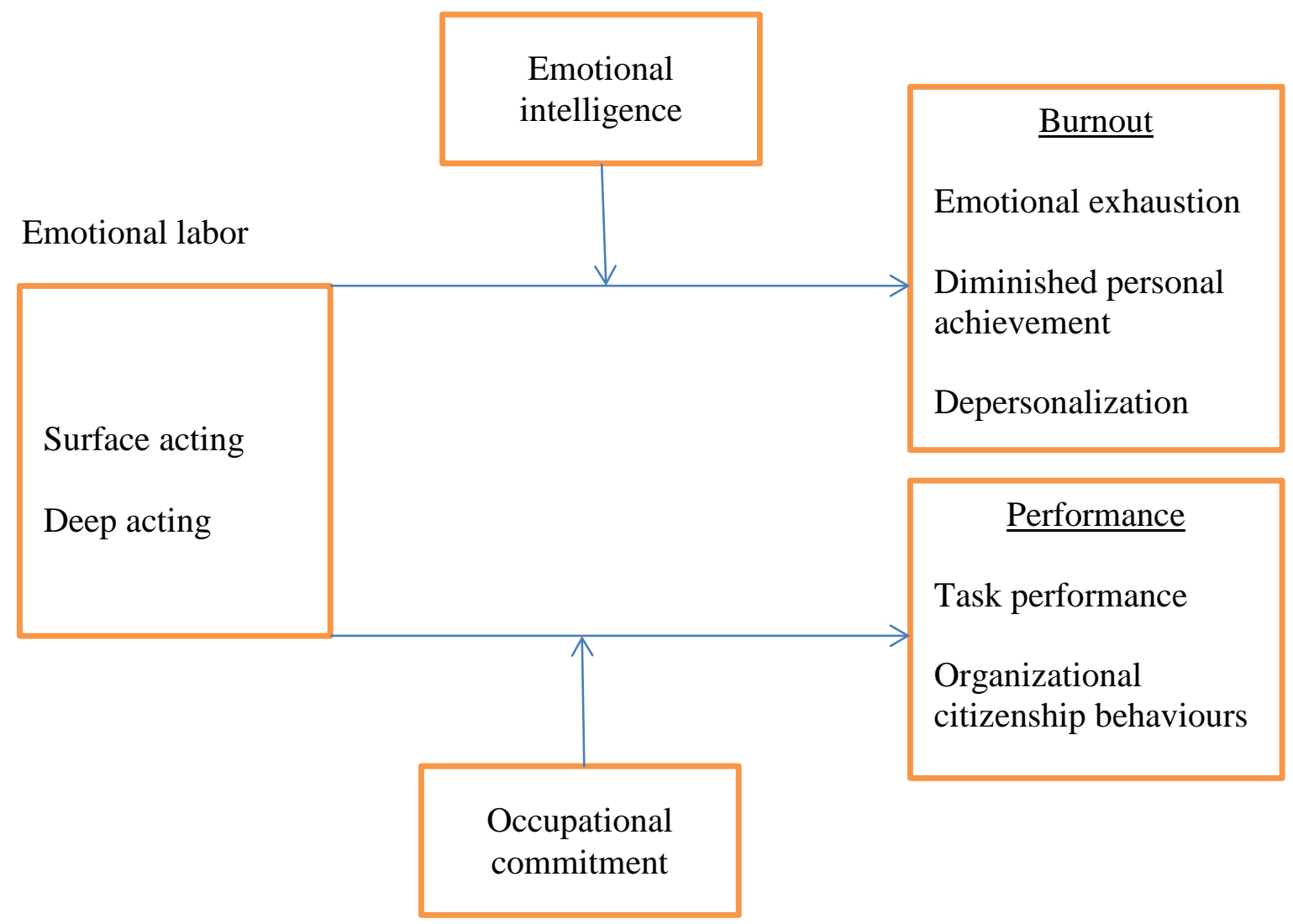

Figure 1

The study model: Emotional labor as the predictor, performance and burnout as the outcome variables, and emotional intelligence and occupational commitment as the moderators. 
Table 1

Confirmatory Factor Analysis results for HELS

\begin{tabular}{|c|c|c|c|c|}
\hline HELS factors and items & $\begin{array}{l}\text { factor } \\
\text { loadings }\end{array}$ & Alpha & $\begin{array}{l}\text { composite } \\
\text { reliability }\end{array}$ & AVE \\
\hline Surface acting & & .76 & .81 & .72 \\
\hline $\begin{array}{l}\text { I put on a mask in order to express the right emotions for my } \\
\text { job }\end{array}$ & .61 & & & \\
\hline $\begin{array}{l}\text { I have to cover up my true feelings when dealing with } \\
\text { customers }\end{array}$ & .59 & & & \\
\hline I display emotions that I am not actually feeling & .62 & & & \\
\hline I fake the emotions I show when dealing with customers & .72 & & & \\
\hline My interactions with customers are very robotic & .51 & & & \\
\hline $\begin{array}{l}\text { I put on an act in order to deal with customers in an appropriate } \\
\text { way }\end{array}$ & .68 & & & \\
\hline I behave in a way that differs from how I really feel & .74 & & & \\
\hline I fake a good mood when interacting with customers & .83 & & & \\
\hline Deep acting & & .78 & .79 & .69 \\
\hline I work at calling up the feelings I need to show to customers & .64 & & & \\
\hline $\begin{array}{l}\text { I have to concentrate more on my behaviour when I display an } \\
\text { emotion that I don't actually feel }\end{array}$ & .51 & & & \\
\hline $\begin{array}{l}\text { I try to talk myself out of feeling what I really feel when } \\
\text { helping customers }\end{array}$ & .71 & & & \\
\hline $\begin{array}{l}\text { I try to change my actual feelings to match those that I must } \\
\text { express to customers }\end{array}$ & .74 & & & \\
\hline $\begin{array}{l}\text { When working with customers, I attempt to create certain } \\
\text { emotions that present the image my company desires }\end{array}$ & .52 & & & \\
\hline $\begin{array}{l}\text { Fit statistics: } \\
\chi^{2}(561)=217.32, \mathrm{p}<.0005 \\
\mathrm{SRMR}=.05 \\
\text { RMSEA }=.05 \\
\text { CFI }=.96 \\
\text { TLI }=.95\end{array}$ & & & & \\
\hline
\end{tabular}


Table 2

Means, Standard Deviations, Inter-correlations and Cronbach Alpha coefficients

\begin{tabular}{|c|c|c|c|c|c|c|c|c|c|c|c|}
\hline Variables & 1 & 2 & 3 & 4 & 5 & 6 & 7 & 8 & 9 & 10 & 11 \\
\hline $\begin{array}{ll}\text { 1. } & \text { surface acting }\end{array}$ & & & & & & & & & & & \\
\hline 2. Deep acting & $-.01^{*}$ & & & & & & & & & & \\
\hline 3. $\mathrm{EE}$ & $.42^{* *}$ & $.10^{*}$ & & & & & & & & & \\
\hline $4 \quad$ DPA & .07 & $.17^{* *}$ & $.37^{* *}$ & & & & & & & & \\
\hline 5 Depersonalisation & $.40^{* *}$ & $.15^{* *}$ & $.71^{* *}$ & $.26^{* *}$ & & & & & & & \\
\hline 6. Task performance & $.14^{* *}$ & -.07 & $-.34^{* *}$ & $-.55^{* *}$ & $-.42^{* *}$ & & & & & & \\
\hline 7. ОСв & .06 & .02 & $-.47^{* *}$ & $-.71^{* *}$ & $-.49^{* *}$ & $.73^{* *}$ & & & & & \\
\hline 8. EI & $.17^{* *}$ & .06 & $-.31^{* *}$ & $-.72^{* *}$ & $-.30^{* *}$ & $.73^{* *}$ & $.66^{* *}$ & & & & \\
\hline 9. Affective OC & $-.09^{*}$ & $-.09 *$ & $-.50^{* *}$ & $-.44^{* *}$ & $-.46^{* *}$ & $.50^{* *}$ & $.55^{* *}$ & $.51^{* *}$ & & & \\
\hline 10 Continuance OC & .07 & .02 & $-.18^{*}$ & $-.15^{*}$ & $-.15^{*}$ & $.09^{*}$ & $.11^{*}$ & $.12^{*}$ & $.36^{* *}$ & & \\
\hline 11 Normative OC & .06 & .04 & -.09 & .07 & -.05 & .08 & .07 & .07 & $.24^{* *}$ & $.28^{* *}$ & \\
\hline Mean & 44.13 & 23.16 & 30.96 & 38.91 & 27.16 & 38.38 & 124.7 & 167.80 & 28.74 & 26.61 & 29.32 \\
\hline Standard Deviation & 8.21 & 7.94 & 12.12 & 8.06 & 6.51 & 8.32 & 23.07 & 29.44 & 7.38 & 6.24 & 7.31 \\
\hline Cronbach Alpha & .77 & .78 & .93 & .86 & .82 & .86 & .93 & .95 & .81 & .89 & .78 \\
\hline
\end{tabular}

$\mathrm{EE}=$ emotional exhaustion, $\mathrm{DPA}=$ diminished personal accomplishment, $\mathrm{OCB}-$ organizational citizenship behaviour, $\mathrm{EI}=$ emotional intelligence, affective $\mathrm{OC}$ = affective occupational commitment, continuance $\mathrm{OC}$ = continuance occupational commitment, Normative OC $=$ normative occupational commitment

**. Correlation is significant at the 0.01 level (2-tailed). ${ }^{*}$. Correlation is significant at the 0.05 level (2-tailed). a. Listwise $\mathrm{N}=578$ 
Table 3

Average variances and shared variance estimates

\begin{tabular}{|c|c|c|c|c|c|c|c|c|c|c|c|c|}
\hline Variables & Items & SA & DA & $\mathbf{E E}$ & DPA & DP & $\mathbf{T P}$ & OCB & EI & AOC & COC & NOC \\
\hline$\overline{\text { SA }}$ & 7 & .72 & & & & & & & & & & \\
\hline DA & 8 & .01 & .69 & & & & & & & & & \\
\hline EE & 33 & .17 & .10 & .61 & & & & & & & & \\
\hline DPA & 6 & .05 & .29 & .14 & .67 & & & & & & & \\
\hline DP & 6 & .16 & .23 & .50 & .07 & .71 & & & & & & \\
\hline TP & 6 & .19 & .05 & .12 & .30 & .18 & .79 & & & & & \\
\hline OCB & 9 & .04 & .04 & .22 & .51 & .24 & .67 & .81 & & & & \\
\hline EI & 7 & .29 & .04 & .09 & .52 & .09 & .53 & .67 & .82 & & & \\
\hline AOC & 6 & .08 & .08 & .25 & .19 & .21 & .25 & .30 & .13 & .67 & & \\
\hline COC & 7 & .05 & .01 & .03 & .02 & .02 & .08 & .12 & .06 & .13 & .63 & \\
\hline NOC & 22 & .04 & .02 & .08 & .04 & .01 & .06 & .05 & .05 & .06 & .08 & .69 \\
\hline
\end{tabular}

Note: AVE estimates are presented on the diagonal in bold. Squared correlations are below the diagonal.

$\mathrm{SA}=$ surface acting, $\mathrm{DA}=$ deep acting, $\mathrm{EE}=$ emotional exhaustion, $\mathrm{DPA}=$ diminished personal achievement, $\mathrm{DP}=$ depersonalisation, $\mathrm{TP}=$ task performance, $\mathrm{OCB}=$ organizational citizenship behaviours, $\mathrm{EI}=$ emotional intelligence, $\mathrm{AOC}=$ affective occupational commitment, $\mathrm{COC}=$ continuance occupational commitment, $\mathrm{NOC}=$ normative occupational commitment. 


\section{Table 4}

The relationships among EL, performance, and burnout

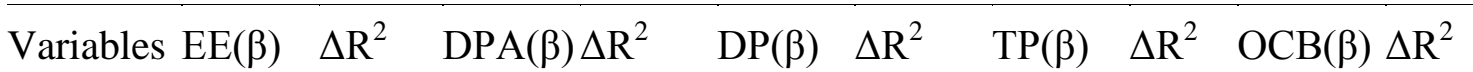

\begin{tabular}{lllllll}
\hline Step 2 & & $.15^{* * *}$ & $.05^{* * *}$ & $.15^{* * *}$ & $.02 * *$ & .01 \\
SA & $.39 * * *$ & $.11^{*}$ & & $.37 * * *$ & $.14^{* *}$ & $.09 *$ \\
DA & $.08^{*}$ & $.12 * * *$ & $.14^{* *}$ & -.04 & .03 &
\end{tabular}

Overall model fit statistics for the analyses

$\begin{array}{lc}\chi^{2} & 663 \\ \text { CFI } & .99 \\ \text { TLI } & .96 \\ \text { SRMR } & .05 \\ \text { RESEA } & .03\end{array}$

Note: $\mathrm{EE}=$ emotional exhaustion, $\mathrm{PA}=$ diminished personal accomplishment, $\mathrm{DP}=$ depersonalisation, $\mathrm{TP}=$ task performance, $\mathrm{Alt}=$ altruism, $\mathrm{CV}=$ civic virtue, $\mathrm{SA}=$ surface acting, $\mathrm{DA}=$ deep acting, ${ }^{*} \mathrm{p}<.05,{ }^{* *} \mathrm{p}<.01,{ }^{* * *} \mathrm{p}<.0005$ 
Table 5

The moderating effects of EI, OC on EL and criterion variables (burnout, task performance and $O C B$ )

\begin{tabular}{lllllll}
\hline Variables & $\mathrm{EE}(\beta)$ & $\Delta \mathrm{R}^{2}$ & $\mathrm{DPA}(\beta)$ & $\Delta \mathrm{R}^{2}$ & $\mathrm{DP}(\beta)$ & $\Delta \mathrm{R}^{2}$ \\
\hline $\mathrm{SA} * \mathrm{EI}$ &.$-36^{* * *}$ & $.11^{* * *}$ & $-.16^{* * *}$ & $.07^{* * *}$ & $-.19^{* * *}$ & $.08^{* * *}$ \\
$\mathrm{DA}$ EI & $-.18^{* * *}$ & $.06^{* * *}$ & $-.09^{*}$ & .00 & $-.19^{* * *}$ & $.08^{* * *}$ \\
\hline Variables & $\mathrm{TP}(\beta)$ & $\Delta \mathrm{R}^{2}$ & $\mathrm{OCB}(\beta)$ & $\Delta \mathrm{R}^{2}$ & \\
\hline SA*AOC & $.18^{* * *}$ & $.07^{* * *}$ & $.16^{* * *}$ & $.07^{* * *}$ & \\
$\mathrm{DA}$ AOC & -.02 & .00 & $.07 *$ & $.01^{*}$ & \\
SA*COC & $.15^{* * *}$ & $.05^{* * *}$ & .02 & .00 & \\
$\mathrm{DA}$ COC & .06 & .00 & .03 & .00 & \\
SA*NOC & .05 & .01 & .05 & .01 & \\
DA*NOC & .02 & .00 & $.06 *$ & .01 & \\
\hline
\end{tabular}

Note: $\mathrm{EE}=$ emotional exhaustion, $\mathrm{PA}=$ diminished personal accomplishment, $\mathrm{DP}=$ depersonalisation, $\mathrm{TP}=$ task performance, $\mathrm{SA}=$ surface acting, $\mathrm{DA}=$ deep acting, $\mathrm{EI}=$ emotional intelligence, $\mathrm{AOC}=$ affective occupational commitment, $\mathrm{COC}=$ continuance occupational commitment, NOC $=$ normative occupational commitment.

${ }^{*} \mathrm{p}<.05, * * \mathrm{p}<.01, * * * \mathrm{p}<.0005$ 


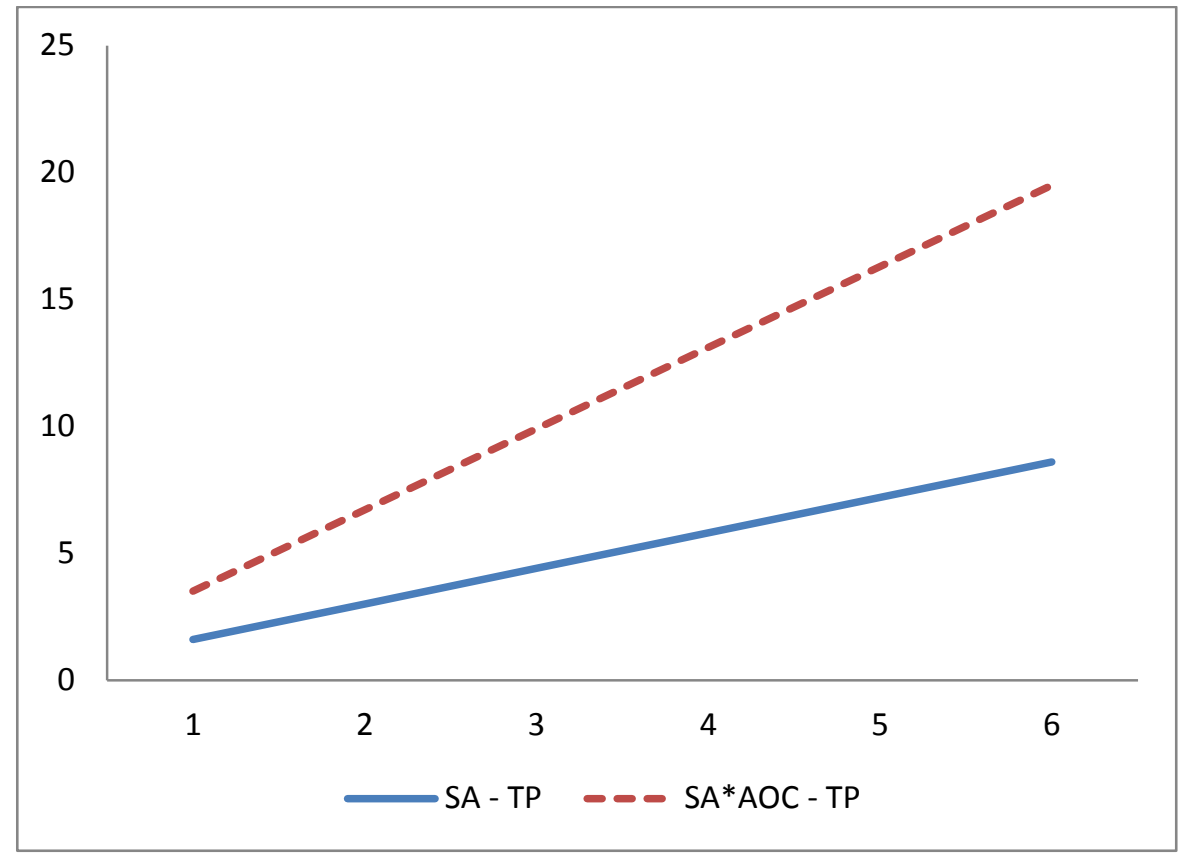

Figure 2. Moderating effect of affective occupational commitment between surface acting and task performance

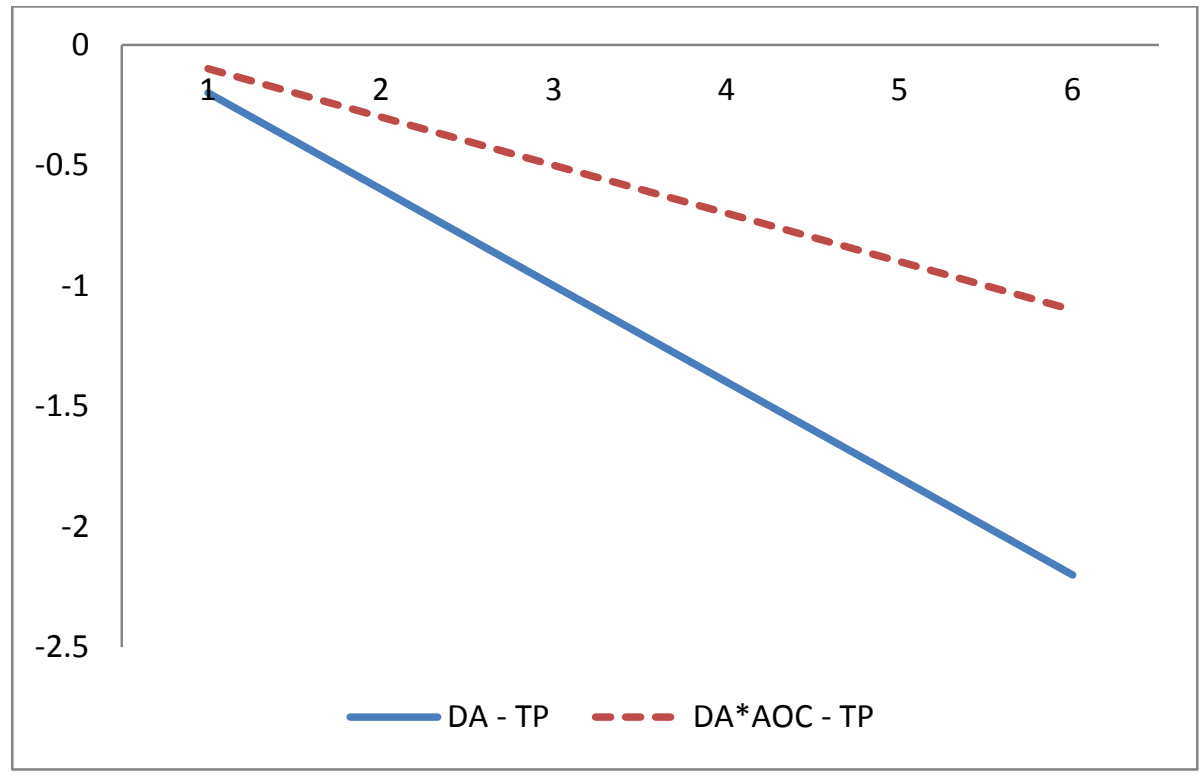

Figure 3. Moderating effect of affective occupational commitment between deep acting and task performance 


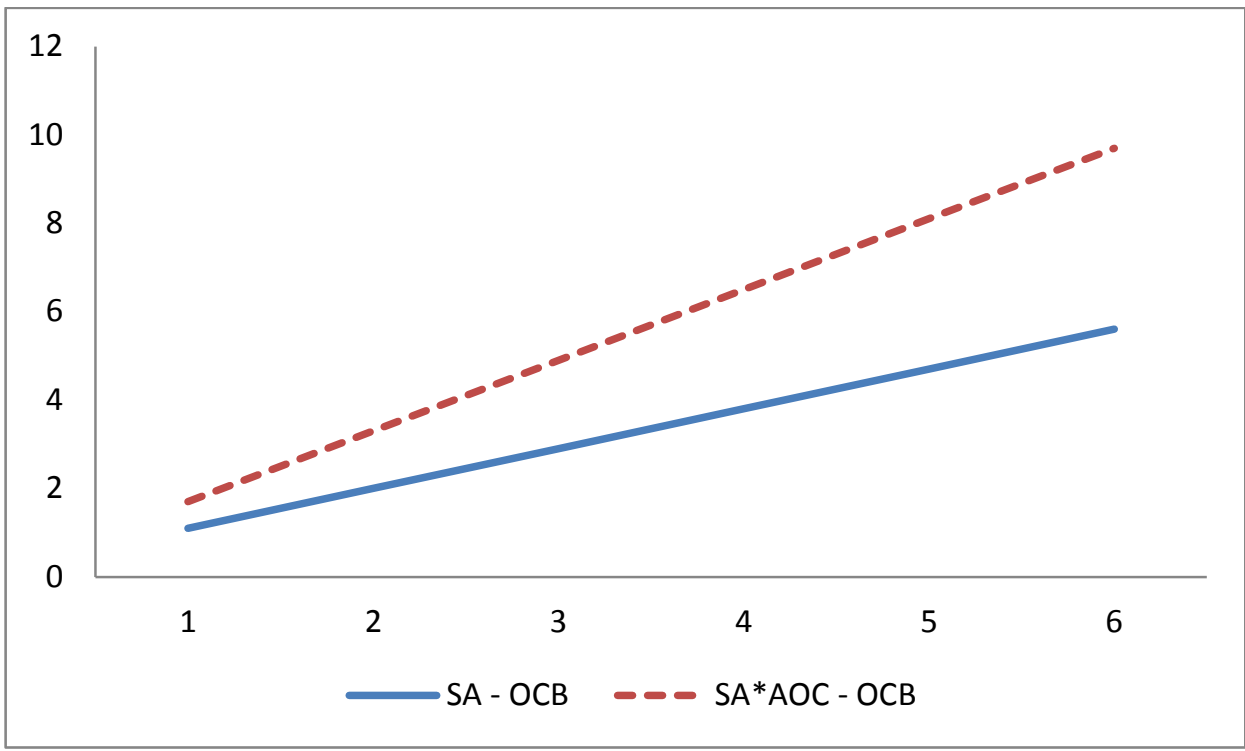

Figure 4. Moderating effect of affective occupational commitment between surface acting and $\mathrm{OCB}$

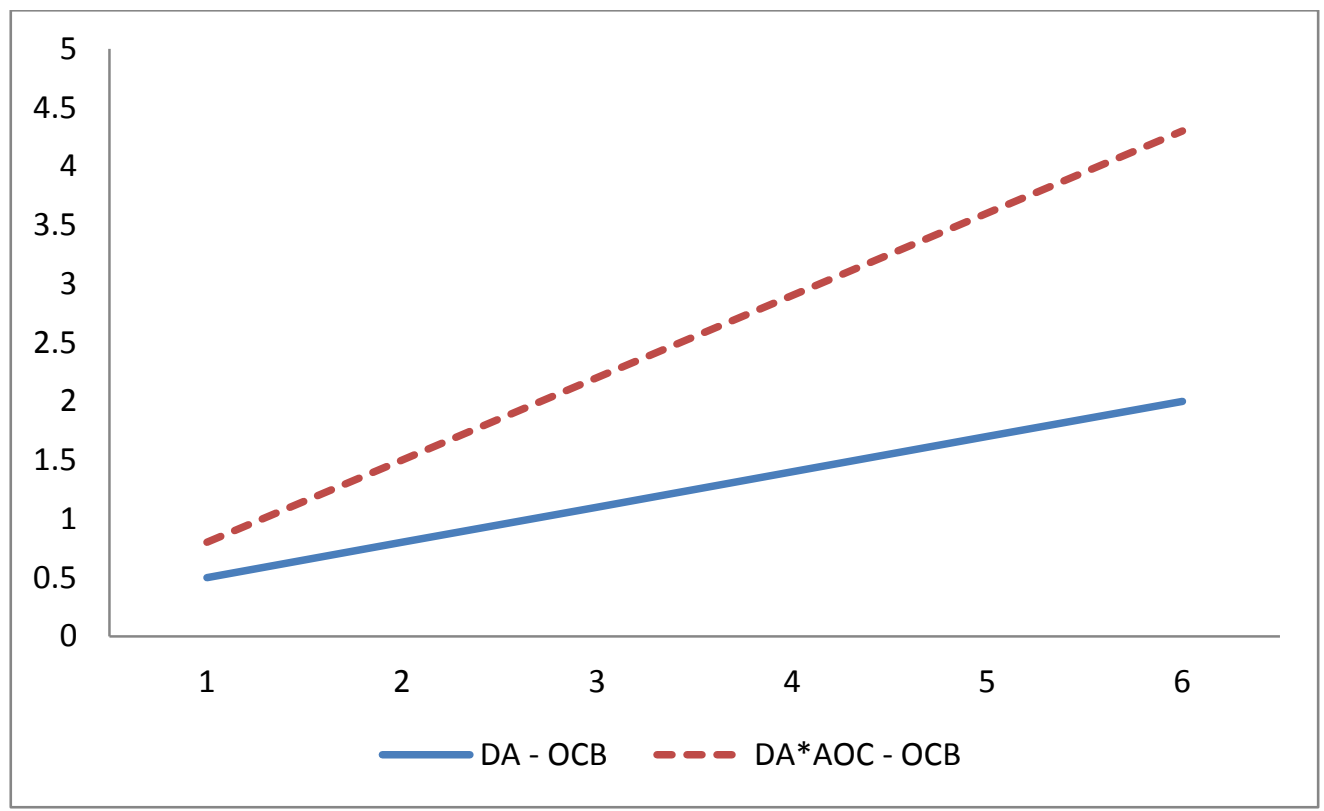

Figure 5. Moderating effect of affective occupational commitment between deep acting and OCB 


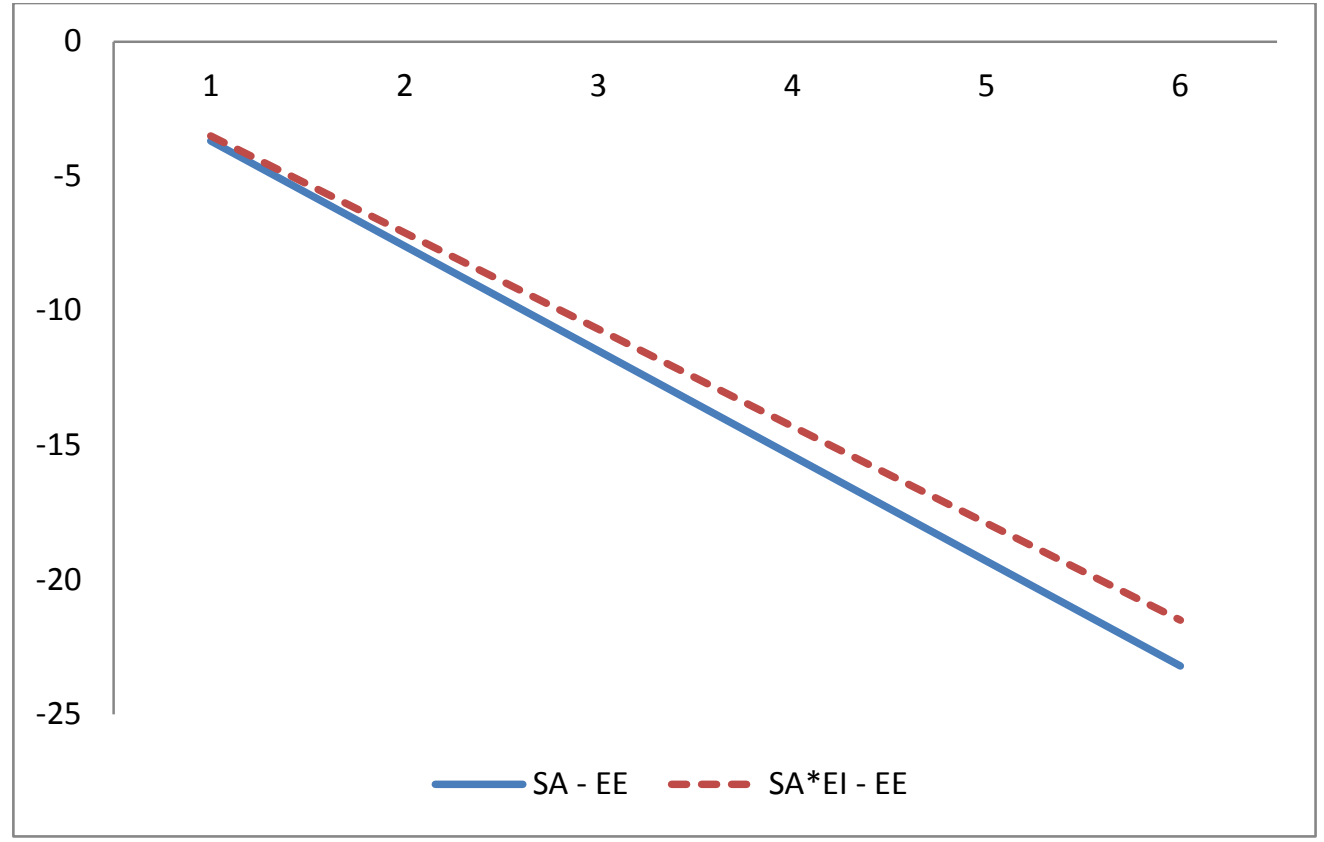

Figure 6. Moderating effect of emotional intelligence between surface acting and emotional exhaustion

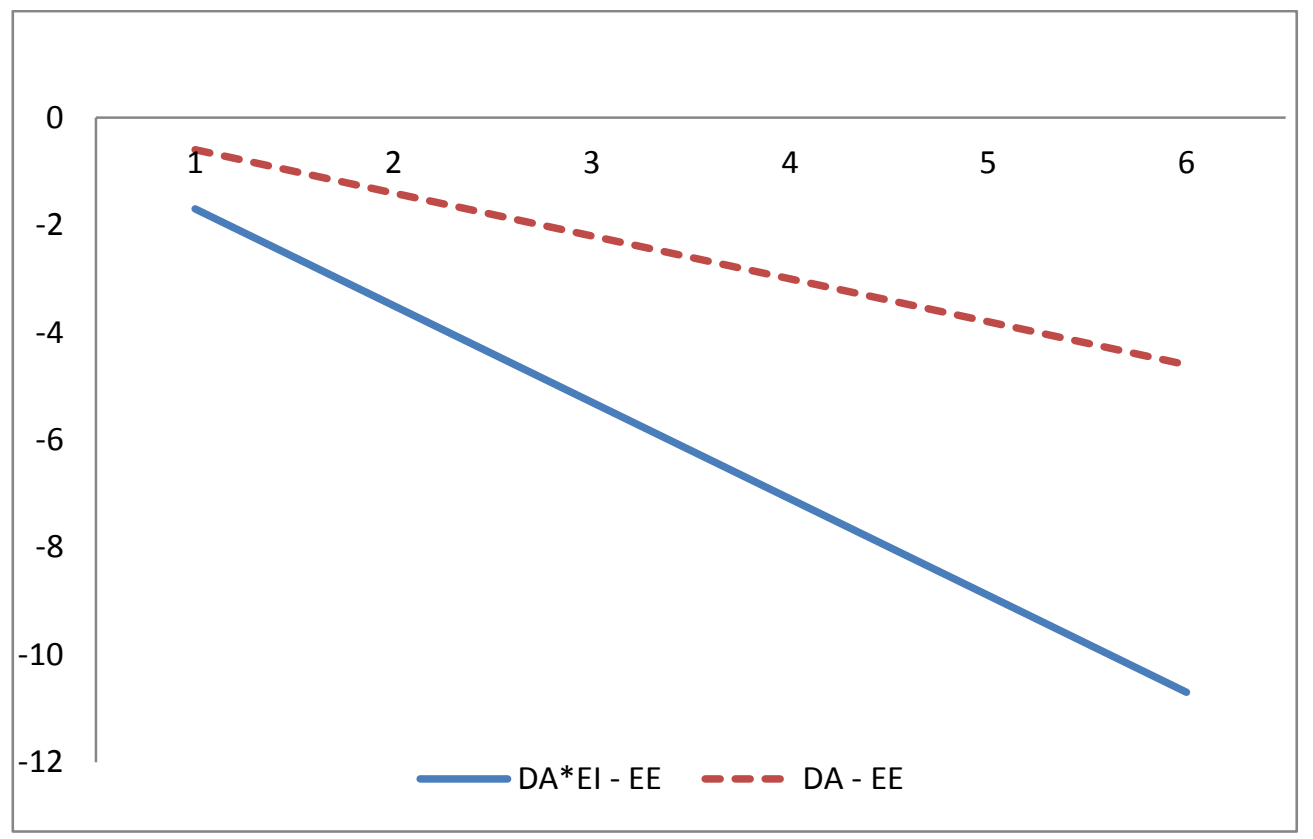

Figure 7. Moderating effect of emotional intelligence between deep acting and emotional exhaustion 


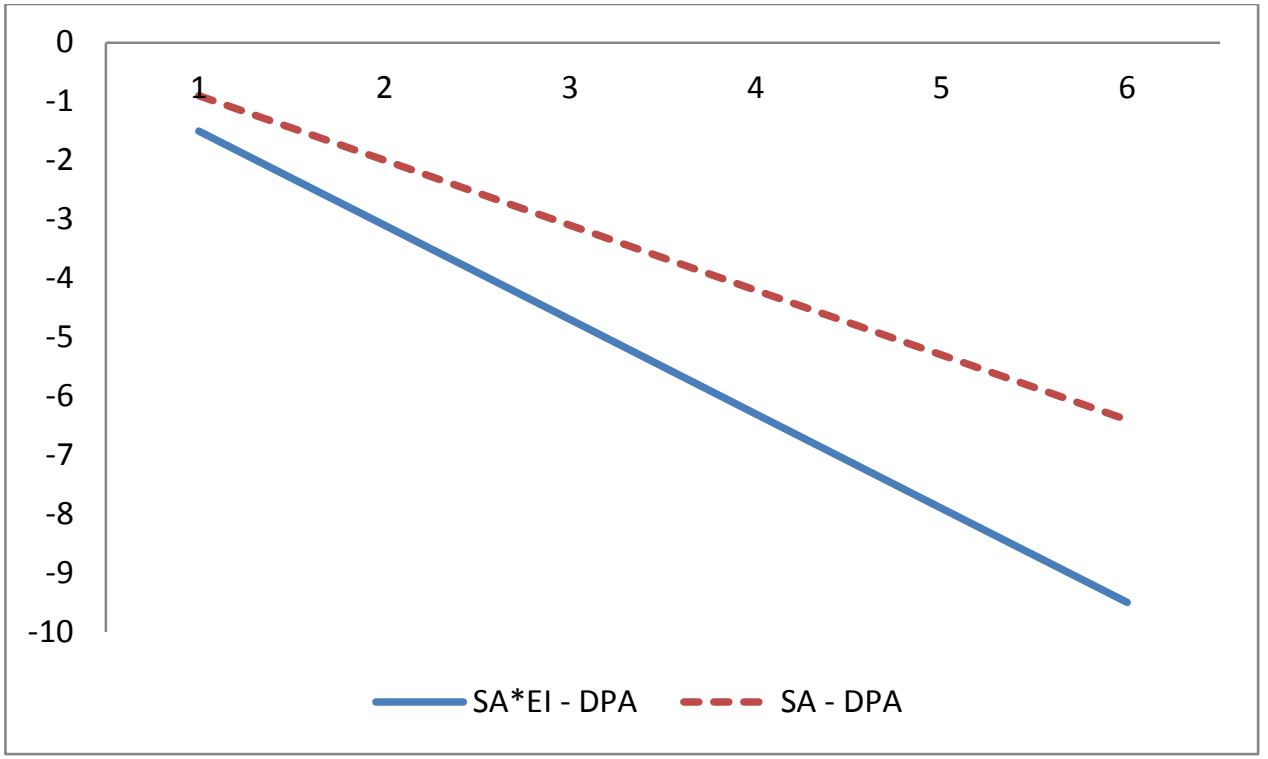

Figure 8. Moderating effect of emotional intelligence between surface acting and deminished performance achievement

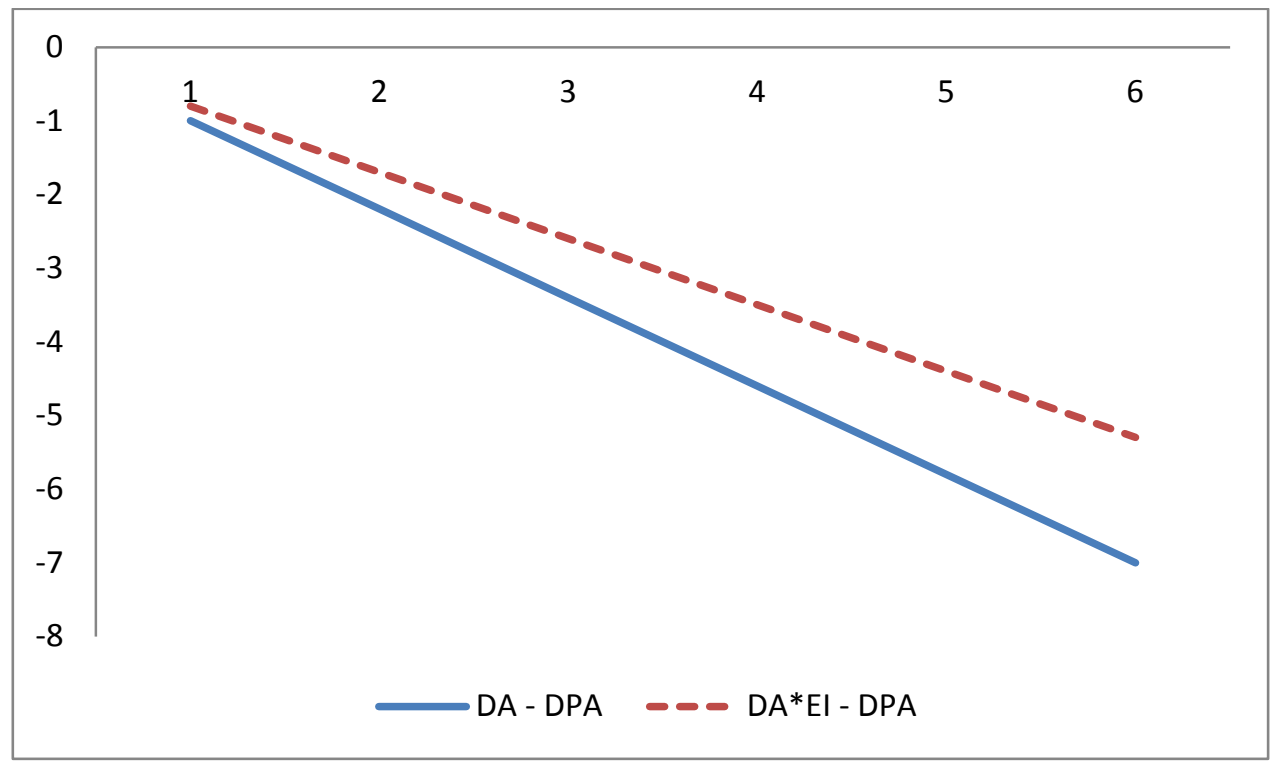

Figure 9. Moderating effect of emotional intelligence between deep acting and deminished performance achievement 


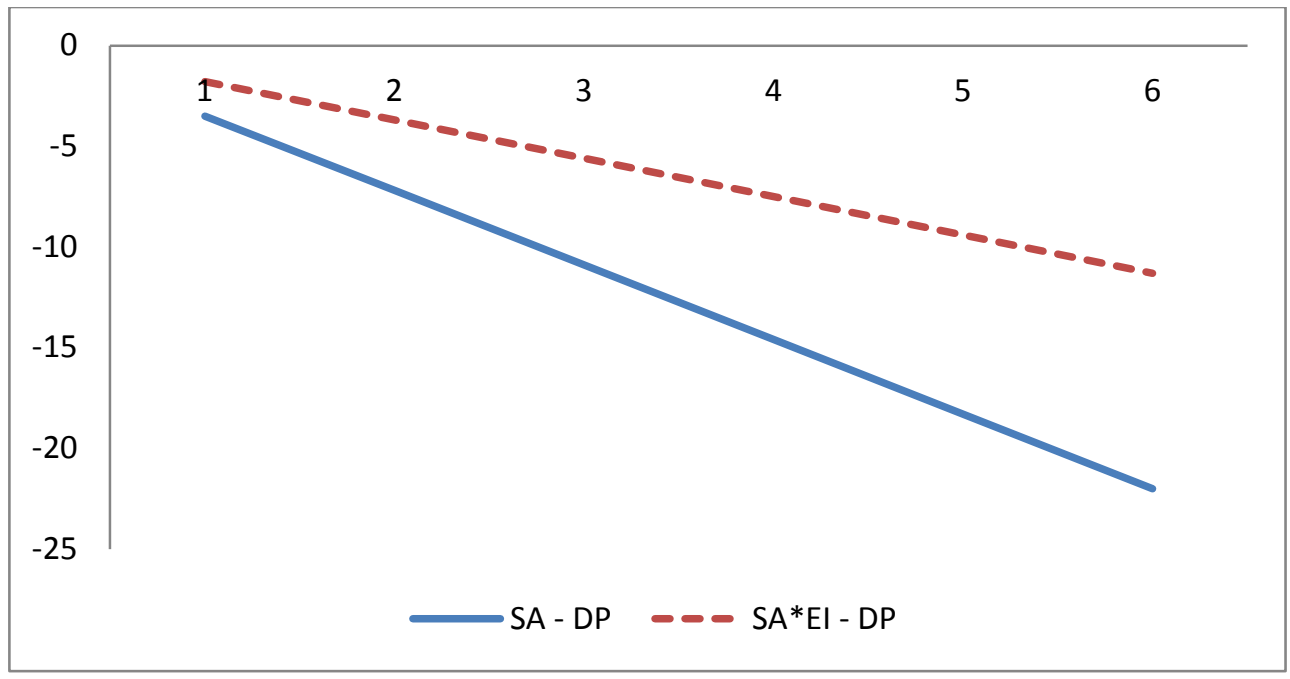

Figure 10. Moderating effect of emotional intelligence between surface acting and depersonalization

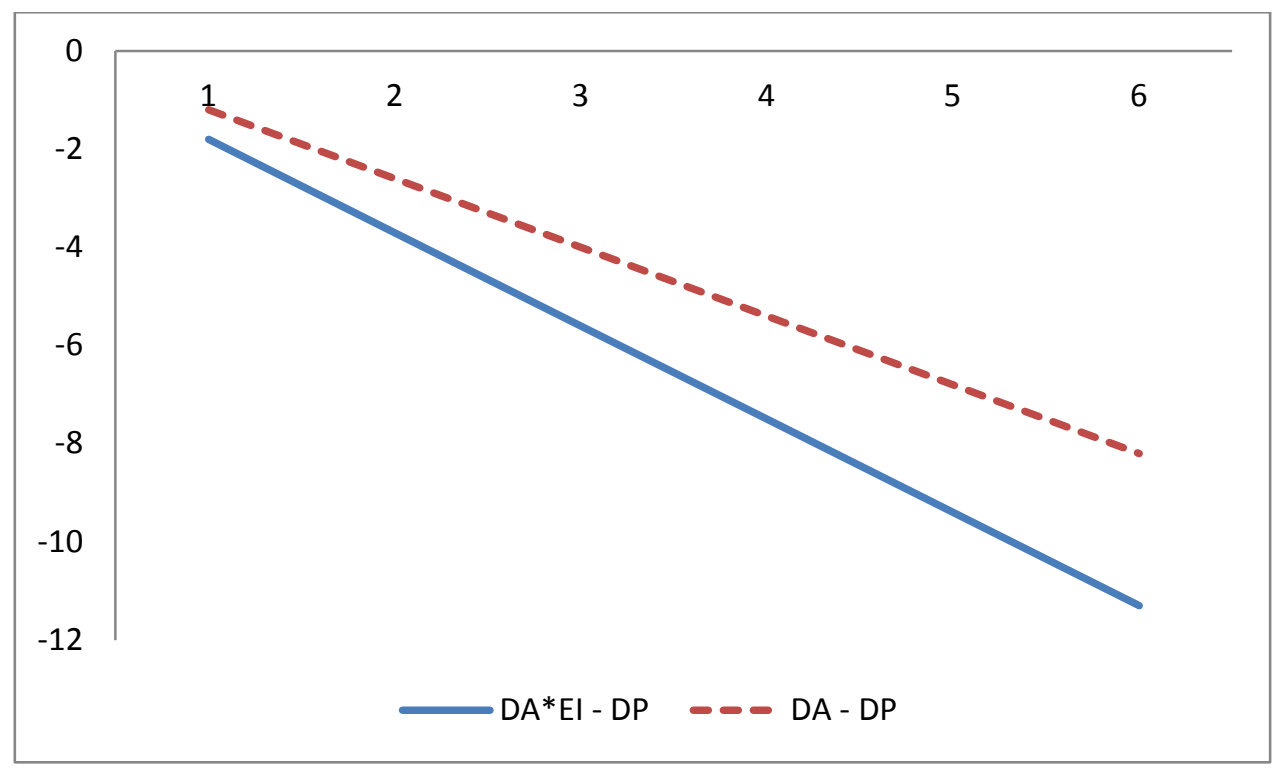

Figure 11. Moderating effect of emotional intelligence between deep acting and depersonalization 